\title{
Sobre monstros e imaginação na sociedade do espetáculo, por Hal Hartley
}

\author{
Ângela Lamas Rodrigues*
}

\begin{abstract}
Resumo: Tomando como base a figura do monstro frankensteiniano, monstro cujos predicados espelham as contradições do capitalismo industrial, os excessos da ciência e a psique do indivíduo fraturado pela modernidade, este trabalho propõe analisar a figura do monstro em No such thing (2001), do diretor estadunidense Hal Hartley. O artigo foca-se, particularmente, na discussão, sugerida no filme, sobre o lugar do monstro num momento histórico em que a mídia, o espetáculo e o consumo deixam pouco espaço para uma figura idealizada pela imaginação humana, que traduz, em última instância, os desejos, as ansiedades e os medos de dada sociedade. O monstro que em geral mata e aterroriza o ser humano é tratado no filme como produto da imaginação artística que expurga os males da alma, ao passo que a hipocrisia, o utilitarismo e a racionalidade científica figuram, na obra, como as verdadeiras monstruosidades que assolam a humanidade num mundo dito pós-moderno. Assim, o monstro em No such thing, personagem imortal atrelado aos valores modernos, é, como em Frankenstein, menos monstruoso que a sociedade contemporânea ultracapitalista na qual sobrevive e da qual é vítima imperdoável.
\end{abstract}

Palavras-chave: Obsolescência do monstro. Pós-modernidade. Frankenstein.

Where is the wisdom we have lost in knowledge?

Where is the knowledge we have lost in information?

T. S. Eliot

\section{Introdução}

O filme No such thing, do diretor estadunidense Hal Hartley, retrata um monstro que se diferencia, em grande medida, daqueles conhecidos pelo espectador. Em termos gerais, pode-se dizer que os monstros do século $\mathrm{XX}$, ainda que apresentem uma ou outra fraqueza, são seres temíveis, cuja força e estrutura constituem ameaças ao homem. Capazes ou não de refletir sobre sua condição ou sobre as consequências de seus atos, tais monstros, sejam eles alienígenas, vampiros, fantasmas ou mortosvivos, carregam uma força destruidora que usam, em geral, para preservarem sua espécie, para se vingarem, ou por se sentirem ameaçados. Segundo Julio Jeha (2007, p. 7-8), "os monstros dão um rosto (ou não) ao nosso medo do desconhecido, que

*Professora da Universidade Estadual de Londrina. Email: alrodrigues73@yahoo.com.br. 
tendemos a associar ao mal a ser praticado contra nós." Além disso, "corporificam tudo que é perigoso e horrível na experiência humana." São, portanto, entidades que traduzem a própria ansiedade do homem a respeito do mal que pode causar ou sofrer.

Em No such thing, porém, o monstro ocupa um lugar diferenciado. Não se trata de um monstro atemorizante - apesar de possuir a potência destruidora de monstros bem conhecidos - mas de um monstro obsoleto e cansado, que simplesmente desistiu da sua condição na Terra. Não figura, portanto, como representação do mal ou do medo do desconhecido. Ao contrário, o monstro de Hal Hartley questiona sua existência e aponta para uma problemática na condição humana. É que, em realidade, Hartley cria um ser que não é um monstro em si, mas a corporificação da ideia de monstro, que remete, por sua vez, à capacidade imaginativa do homem. Esta capacidade, que parece definhar numa sociedade de consumo sem reflexão, é o que dá vida ao monstro. Ele é, assim, uma metáfora para a imaginação humana. Na medida em que o homem deixa de imaginar e sonhar, o monstro se enfraquece e tende a desaparecer por completo.

A banalização da vida e das relações afetivas no mundo dito pós-moderno é uma constante nos filmes Hartley. Em No such thing, a temática é tratada de forma alegórica a partir de um enredo focado na redenção de um monstro que busca pelo seu aniquilamento em meio a uma sociedade hipócrita e destituída da sabedoria necessária para entender a condição de tal criatura.

\section{Obsolescência do monstro na pós-modernidade}

A primeira cena de No such thing apresenta-nos um monstro em decadência, que reconhece de saída sua inadequação ao mundo contemporâneo: "Não sou o monstro que costumava ser. Admito isso. Estou cansado, mais fraco, estou perdendo minha memória e não consigo dormir". ${ }^{1}$ Figura supostamente eterna, que não recorda seu próprio nascimento, o monstro, agora um alcoólatra entediado, implora por um fim que não lhe é concedido.

Em uma de suas falas, o monstro explica sua condição na Terra:

Eu me lembro de quando vocês [humanos] eram jovens, um líquido qualquer na beira de uma poça de água morna. Eu estava lá, assistindo. Eu vi vocês se desenvolverem. Completamente entediado, eu suspirava e esperava enquanto vocês levaram milênios pra se transformarem em peixe (...). Patético. Eu costumava ir às suas pequenas vilas, pegar alguém de baixa estatura ou uma criança, quebrar suas cabeças nas rochas e olhar, estudar, tentando entender como vocês eram, o que tornava vocês - imbecis - tão adaptáveis. Mas não havia nada: sangue, tripas e merda, o mesmo que todo o resto. Sem propósito. Absurdo. Só um outro acidente. Eu costumava ficar nos rochedos à noite, sentado, olhando as estrelas e perguntando o que seria de mim. Será que eu viveria pra sempre? Eu quero morrer, mas não posso. Sou indestrutível.

\footnotetext{
${ }^{1}$ As traduções para o português foram realizadas pela autora.
} 


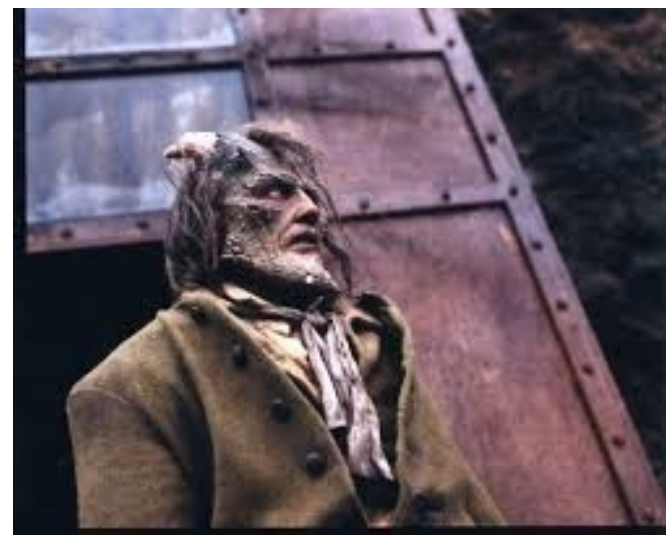

Figura 1: O monstro em sua moradia na Islândia

Sua vida entediante é radicalmente transformada quando a jovem Beatrice chega à ilha onde se esconde, nos confins da Islândia. Beatrice vai à ilha para descobrir o paradeiro do seu noivo que teria sido assassinado pela criatura misteriosa. A princípio, a protagonista revolta-se contra o monstro, mas acaba por tornar-se sua grande aliada no decorrer da história. Beatrice e o monstro - uma referência ao conto A Bela e a Fera e ao amor de Dante e Beatrice em A divina comédia - saem das geleiras nórdicas e chegam à Nova York para que o monstro possa encontrar Artaud, o único homem supostamente capaz de pôr fim à sua vida angustiante e solitária.

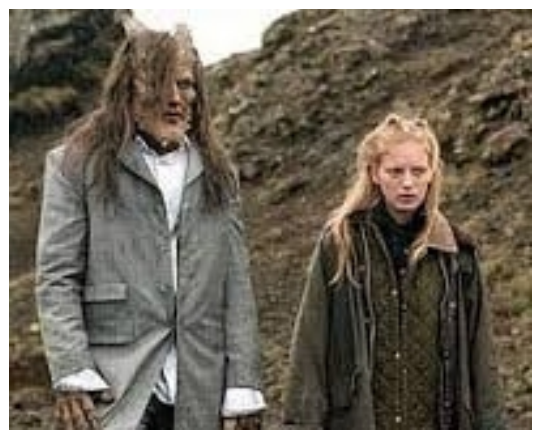

Figura 2: O monstro e Beatrice

Como já mencionado, o monstro de Hartley é um ser que não mais amedronta ou aterroriza. É, como diz uma das personagens do filme, "irrelevante", no mundo atual. Tal mundo é representado pelo diretor a partir de uma perspectiva que enfatiza a superficialidade das relações humanas, o espetáculo da imagem e a especulação financeira. Trata-se, em outras palavras, do mundo pós-moderno que o crítico estadunidense, Fredric Jameson, entende como constituído pela fragmentação, pela falta de profundidade, pela intensidade e pelo hibridismo, características de um tempo histórico que sucumbiu às demandas do capitalismo tardio. Em The cultural turn, o crítico afirma que tais predicados fundamentam o pensamento pós-moderno. $O$ homem vive fragmentos de vida numa sequência de presentes experenciados intensamente, mas sem qualquer percepção de continuidade histórica. Isto produz, em última instância, uma perda de profundidade na produção cultural e no modo de vida como um todo (JAMESON, 1998, p. 50-72). 
Não é a toa que o monstro de Hartley aparece nesse cenário como entidade estranha e fora de moda, que desperta só momentaneamente o interesse da população de Nova York, até deixar de ser manchete nos jornais. Mas o monstro é, antes de tudo, um sábio e um conhecedor profundo do coração e, portanto, da mediocridade e da monstruosidade humanas. O monstro de No such thing viu o homem surgir, rastejar, guerrear, construir e destruir o mundo e a si próprio. Consiste, assim, na única testemunha da história humana, história que lhe produz uma invariável sensação de tédio e desprezo pelos homens. Sua grande angústia é não poder se extinguir e se livrar do mal estar que lhe causa o mínimo contato com a bestialidade, a imbecilidade e a crueldade do ser humano. Tais atributos do humano são evidenciados no filme, sobretudo, na personagem denominada The Boss, proprietária do maior jornal nova-iorquino: gananciosa, egoísta e autoritária, a personagem é virtualmente capaz de qualquer coisa para publicar o próximo "furo" jornalístico e manter a posição do seu jornal garantida. É ela que promete à Beatrice, sua funcionária, encontrar Artaud para ajudar o monstro, que implora para morrer. Mas seu interesse nada mais é que transformá-lo em mais um espetáculo e atração na mídia. E quando recebe uma proposta do governo, que pretende estudar o monstro, não hesita em entregá-lo às autoridades.

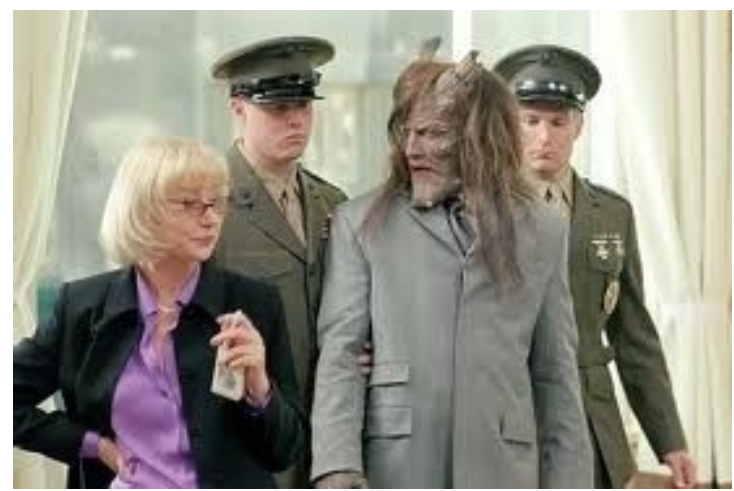

Figura 3: The Boss trai o monstro e o entrega ao governo dos Estados Unidos

O monstro torna-se então cobaia e vítima dos mais hediondos experimentos. Segundo o cientista encarregado da pesquisa, "o monstro é capaz de suportar a tortura que lhe está sendo imposta indefinidamente." Na sequência, o monstro é posto nas ruas para que a pesquisa seja feita em campo, por assim dizer. Solto em meio à população, o monstro é humilhado, espancado e torturado até que Beatrice consegue resgatá-lo. Ambos voltam para o norte da Islândia, agora com Artaud, que cria uma máquina capaz de desintegrar o monstro e por fim à sua vida miserável.

Segundo o cientista encarregado dos experimentos nos laboratórios do governo dos Estados Unidos, o monstro possui apenas uma fraqueza: não suporta qualquer carga de informação. Esse é um dado curioso, que remete aos versos de T. S. Eliot na epígrafe do presente ensaio e, mais uma vez, à ideia de pós-modernidade como definida por Jameson. Muito embora a noção de mundo pós-moderno seja controversa e debatida por muitos, No such thing, parece-me, não deixa dúvidas sobre sua posição 
crítica a respeito de um modo de vida que enaltece o espetáculo, entendido, aqui, nos termos de Guy Debord (1967, p. 6-13) enquanto "resultado e objetivo do modo de produção existente", que "afirma que toda vida humana, ou seja, toda vida social, é meramente aparência". Para o escritor, "em todas as suas formas específicas, como informação ou propaganda, anúncio ou o consumo direto do entretenimento, o espetáculo é o presente modelo da vida social dominante. É a afirmação onipresente da escolha já feita na produção e sua consumação corolária". A ênfase, no filme, à dinâmica da mídia, que literalmente despreza e negligencia qualquer tragédia ou calamidade, transformando-as em meras informações que precisam ser recicladas no dia seguinte, e o fato de tais informações condicionarem a vida social, política e econômica do globo, é um bom exemplo do que Debord considera uma sociedade que se alimenta do espetáculo. Tem-se, neste contexto, uma sociedade em que o afeto foi substituído pela intensidade, para voltar a Jameson. Ou seja, os sentimentos complexos, duradouros e constituídos no tempo, como processos, são dispensados e trocados pela intensidade e superficialidade dos encontros e sensações momentâneos, que rejeitam a história e a possibilidade de qualquer aprofundamento ontológico. Saber do outro ou de mim mesmo, ver a dor e o sofrimento do mundo, ouvir a história, o relato, a violência por trás dos fatos, tudo isso se torna absolutamente dispensável, ou melhor, obsoleto, no ceio da sociedade do espetáculo. O que importa é o efeito instantâneo da notícia, da propaganda, da imagem e, obviamente, o seu consumo, físico ou ideológico.

O monstro de Hartley não suporta a informação justamente por ela ser contrária à sua natureza. Sua sabedoria, que o leva a detestar o humano, rejeita a informação rápida, fragmentada e rasa. Como veremos mais adiante, essa pode ser uma metáfora para a figura do monstro enquanto elemento que remete à sensibilidade e à afeição no humano, metáfora que vai na contramão do monstro ameaçador do século XIX. Em suma, o filme propõe um monstro que, ao ser ridicularizado e banalizado pelo humano, aponta para a própria mediocridade de um homem que nega seus afetos e sua imaginação.

\section{O monstro e a criatura Frankensteiniana}

Lançado em 2001, No such thing apresenta uma figura monstruosa distinta, em vários aspectos, de monstros produzidos em outros momentos históricos, incluindo os monstros do século XIX. No entanto, é possível traçar um paralelo produtivo, por semelhança e diferença, entre o monstro de Hartley e a Criatura em Frankenstein; ou O Moderno Prometeu, de Mary Shelley. Note-se, a princípio, que o trajeto percorrido pelo monstro e sua amiga é inverso àquele traçado pela Criatura de Victor Frankenstein, que sai da cidade para refugiar-se no Ártico. Mais que isso, os dois monstros são paradoxais em sua relação com o humano. Como pontua Sérgio Bellei (2000, p. 33), a respeito do romance de Mary Shelley, "ao mesmo tempo monstruoso e mais humano do que Victor, a criatura é um ser sem lugar que, em sua vigorosa rebeldia, simultaneamente confirma a normalidade e aponta para suas limitações". Em Monstros, índios e canibais, Bellei comenta que os monstros do século XIX, como é o 
caso, por exemplo, da Criatura de Victor Frankenstein e Drácula - diferentemente de seres monstruosos criados e pensados no período medieval, em que o monstro configurava a ponte entre o humano e o divino, e no classicismo, momento em que o monstro era sempre um ente controlado pelos poderes da razão - estão inquestionavelmente fora do controle humano. Cabe lembrar que o homem do século XIX é um questionador dos supostos benefícios da Revolução Industrial e da racionalidade científica. Os escritores românticos exploraram o problema a fundo, questionando a insuficiência da razão e instigando o leitor a reconsiderar o lugar da imaginação na vida humana industrializada. Pois são essas inseguranças, incertezas e conflitos que fazem surgir, na literatura, o monstro perigoso, sem controle e dominador:

\begin{abstract}
O processo de descentramento, fragmentação e perda da capacidade de controle do humano [inaugurado pelo romantismo] intensifica-se com o correr do tempo e prolonga-se possivelmente até nossos dias, em um percurso histórico bem conhecido e que passa tanto pelas descobertas de Darwin e Freud como pelo pensamento de Marx e Nietzsche. (...). Tudo indica que é nesse contexto de incerteza crescente que o monstro parece prosperar com força e autonomia anteriormente desconhecidas. (BELLEI, 2000, p. 27).
\end{abstract}

É certo que o monstro de Hal Hartley caracteriza-se, também, como um ser deslocado, a quem foi negada qualquer forma de pertencimento. Mas o monstro, além de ter perdido sua autonomia e força, diferencia-se da criatura de Frankenstein, sobretudo, por não ter sido artificialmente criado por humanos. A criatura de Frankenstein é, por excelência, o produto de uma arrogância do humano que se pretende criador e não encontra limites para a satisfação de seus desejos e impulsos vaidosos e violentos. Em certa medida, o poder de destruição da criatura, incontrolável em sua força e angústia, é em si uma metáfora para a violência implicada em sua constituição, para o horror do seu nascimento, e para a crueldade da sociedade e de seu pai-criador. Como lembra Sílvia Quinteiro (2006, p. 77), "a criatura de Frankenstein encontra a origem da sua monstruosidade em duas causas distintas: nos actos do criador/transgressor que Ihe dá uma vida não-natural e nos actos do grupo ou sociedade que neste caso a rejeitam e perseguem devido à sua diferença $e$ que a levam a reagir de modo terrível".

No decorrer da obra, a criatura acaba por espelhar a maldade de Frankenstein, destacando-a, e mostrando-a como a fonte mesma do mal ou da monstruosidade. 0 humano, nesse contexto, é pior que o monstro ou é a própria monstruosidade encarnada, se entendermos a monstruosidade como expressão da maldade causadora de sofrimento intenso. Assim como o monstro, o mal foi também, e historicamente, definido e pensando de diversas maneiras, mas me atenho aqui ao mal como o encontro de uma intenção de produzir sofrimento (ou mesmo da frieza ou negligência em relação à dor do outro) e os efeitos da ação maldosa. Para Victor, não importava como a sua criatura se sentiria e habitaria o mundo. Antes estava sua vaidade e seu orgulho por se sentir capaz de produzir algum tipo de vida, artificialmente, a partir de seus conhecimentos científicos. O mal, neste caso, reside nesta união entre causa (orgulho, vaidade, egoísmo, insensibilidade e frieza em Victor) e efeito (violência, ira e 
angústia na Criatura). Este último ponto, a angústia (do alemão Angst, medo), parece ser o ponto nodal para o entendimento da Criatura e de suas ações, que são produzidas, em última instância, pelo abandono, pelo desconhecimento, pela incerteza e pelo deslocamento num mundo assustador. Pois se a Criatura perturba e assusta o mundo, o mundo a aterroriza e produz, assim, uma reação defensiva. Mais uma vez, é o humano que figura em Mary Shelley como monstro portador de uma maldade inexorável. Tristemente, a Criatura é bombardeada pela maldade humana no processo de sua constituição, na sua formação moral e no seu destino.

Ao contrário da Criatura pensada por Mary Shelley, o monstro, em sua solidão, viu o homem surgir e perecer. Mas como em Frankenstein, o monstro de No such thing é mais humano que o próprio homem. Nesse sentido, o conceito de monstruosidade é também invertido para abarcar as perversidades, os sadismos, as atrocidades, em uma palavra, a maldade humana praticada em qualquer grau de consciência contra o indefeso, o diferente, o exótico. Tomada dessa perspectiva, o monstro pode simplesmente não ser monstruoso, ao passo que o príncipe encantado pode ser o mandante ou o praticante de crimes hediondos. É justamente esse conflito entre monstro e monstruosidade que No such thing explora com cuidado e inteligência ao introduzir a figura do monstro numa sociedade em que o lucro, o consumo e a hipocrisia são os pilares das relações interpessoais. Vale dizer, se o monstro do século XIX aterrorizava e exigia um espaço numa sociedade que, muito embora insistisse em marginalizá-lo, reconhecia sua existência e sua constituição híbrida de humano e nãohumano, o monstro de Hartley é meramente um espetáculo, uma imagem de consumo temporário. Como qualquer outra mercadoria, o monstro vira manchete nos jornais e atrai a atenção de jornalistas e da população em geral para ser efetivamente esquecido nas semanas seguintes na medida em que deixa de ser notícia e é substituído por fatos mais recentes e interessantes.

\section{Considerações finais: "No such thing as monsters"}

No livro Monstros e monstruosidades na literatura, Jeha (2007, p. 21) enfatiza que os "[m]onstros fornecem um negativo da nossa imagem de mundo, mostrandonos disjunções categóricas. Dessa maneira eles funcionam como metáforas". Podem ser entendidos, portanto, como figuras narrativas que, a partir da junção de elementos desconexos, dizem aquilo que a linguagem ordinária não consegue traduzir. No caso dos monstros do século XIX pode-se pensar em uma metáfora para a "degenerescência do humano" num contexto Iluminista em que o antropocentrismo atinge níveis antes inimagináveis e a racionalidade científica torna-se o pilar do saber e da relação do homem com a natureza (JEHA, 2007, p. 23). A ideia de monstro como metáfora para a degenerescência humana ou mesmo como entidade que concentra as mazelas e sofrimentos humanos, reais e imaginários, ganha em Hartely um outro sentido. Ou melhor, há no monstro de Hartley um outro desdobramento metafórico, na medida em que representa a capacidade humana de sonhar, abstrair e escapar de um mundo pasteurizado. O monstro de No such thing significa, dessa forma, uma verticalização ou um aprofundamento das relações e percepções humanas. As últimas palavras do personagem Artaud são reveladoras: 
Mas como será o mundo sem monstros? Esses monstros somos nós mesmos, nossa esperança e medo. Nós o criamos e ele nos matou em nosso sono. Nós enxergamos que éramos humanos. Ele não se lembra de seu começo porque começou conosco ... foi formado com nossa história. Somos tão cruéis, eu creio, não por matá-lo, mas por colocar essa responsabilidade em seus feios ombros em primeira instância. Ele não pediu por isso. Somos tão bons nisso. Damos vida às coisas para nos convencermos de nossa existência e agora cometemos o mais horrível dos ataques: matar uma criatura provando pra ela que ela é um figmento da nossa imaginação.

Para o diretor, esse parece ser o grande mal do século. O homem pós-moderno é, em Hartley, um ser horizontal, vazio e sem afeto. É por isso que o monstro está decadente e sofre nos confins do mundo, já não aterroriza e torna-se meramente um objeto de consumo, seja nos laboratórios ou na mídia. O fim do monstro é, assim, o fim do homem como ser sensível. É, por assim dizer, o fim da humanidade no homem e de sua sabedoria. O perigo, portanto, já não reside no monstro em si, mas no seu desaparecimento. "No such thing as monsters", diz Beatrice, num momento de incredulidade absoluta. Mas ele existe e persiste nos recessos do coração humano que a racionalidade científica insiste em negar. Para o espectador, fica a dúvida sobre se a máquina de Artaud funcionará e se o monstro será de fato aniquilado, um resto de esperança, talvez, para a humanidade.

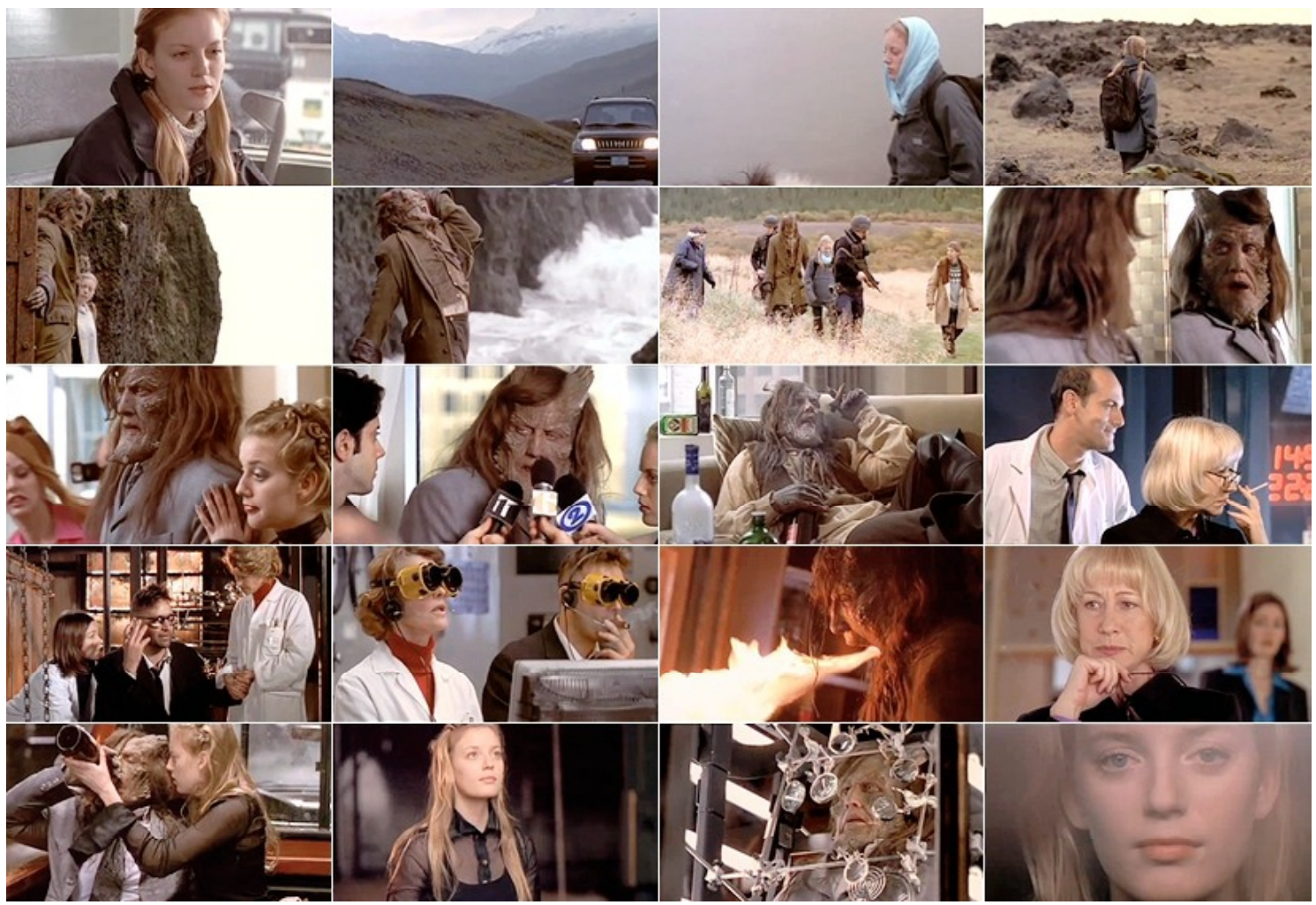




\section{Bibliografia}

BELLEI, S. L. P. Monstros, índios e canibais: ensaios de crítica literária e cultural. Florianópolis: Insular, 2000.

DEBORD, G. La société du spectacle. Paris: Éditions Buchet-Chastel, 1967.

JEHA, J. (org.). Monstros e monstruosidades na literatura. Belo Horizonte: Editora da UFMG, 2007.

JAMESON, F. Postmodernism or the cultural logic of late capitalism. Durham: Duke University Press, 2001.

1998.

The cultural turn: selected writings on the postmodern. London: Verso,

QUINTEIRO, S. Processos de construção da figura monstruosa. Textos e Pretextos, v. 8, 2000, p. 72-81.

SHELLEY, M. Frankenstein; or, the modern prometheus. London: Collector's Library, 2004.

\section{Filmografia}

No such thing. Dir. Hal Hartley. United Artists, 2001.

Title: Of monsters and imagination in the society of the spectacle, by Hal Hartley

Abstract: Based on the Frankensteinian monster, whose predicates mirrors the contradictions of industrial capitalism, the excesses of science and modernity's fractured individual's psyche, this work purports to analyze the character of the Monster in the movie No such thing (2001), by American director Hal Hartley. The article focuses, particularly, on the discussion, suggested in the movie, about the place of the monster in a historical moment in which the media, the spectacle, and consumerism leave little space to an entity idealized by human imagination, an entity that translates, ultimately, the desires, anxieties and fears of a given society. The monster that usually kills and terrorizes men is treated in the movie as a product of an artistic imagination that expels the evils of the soul, whereas hypocrisy, utilitarianism and scientific rationality figure as the real monstrosities that assault the so-called postmodern world. Thus, the monster in No such thing, an immortal character attached to modern values, is, like Frankenstein, less monstrous than the contemporary, ultra-capitalist society in which he still survives and which has transformed him into its unpardonable victim.

Keywords: Obsolescence of the monster. Postmodernity. Frankenstein.

Recebido em: 02/09/2013. Aceito em 30/11/2013 